\title{
原著
}

\section{頸部頸動脈粥状硬化症の病理学的所見から見た 脳虚血の発症機序}

\author{
深尾＼cjkstart繁治， 橋本 信夫, 塚原 徹也 ${ }^{1}$ \\ 緒方 絢, 由谷 親夫, ${ }^{3}$ 米川 泰弘 ${ }^{4}$
}

\section{The Role of the Carotid Artery Plaque: Pathogenesis of Cerebral Ischemia}

\author{
Shigeharu Fukao, M.D., ${ }^{1}$ Nobuo Hashimoto, M.D., ${ }^{1}$ Tetsuya Tsukahara, M.D., \\ Jun OGata, M.D., ${ }^{2}$ Chikao Yutani, M.D., ${ }^{3}$ and Yasuhiro Yonekawa, M.D. ${ }^{4}$ \\ ${ }^{1}$ Department of Neurosurgery, ${ }^{2}$ Research Institute, and ${ }^{3}$ Department of Pathology, \\ National Cardiovascular Center, Osaka, Japan, and ${ }^{4}$ Department of \\ Neurosurgery, University Hospital of Zurich, Zurich, Switzerland
}

\begin{abstract}
Summary : Forty-five carotid artery plaques (27 symptomatic, 18 asymptomatic) were obtained from carotid endarterectomies ( 25 unilateral, 10 bilateral) in 35 patients and were evaluated pathologically. We investigated the relationship of morphologic characteristics to the presence of cerebral ischemic symptoms and to the degree of stenosis associated with the carotid plaques. Simple fibrous plaques were found in 18 of the 45 plaques (40.0\%) and were more frequently observed among the asymptomatic plaques $(55.6 \%)$ than among the symptomatic plaques $(29.6 \%)$. Ulceration was observed in 14 of the 45 plaques (31.1\%) and was more frequent in plaques from symptomatic cases (44.4\%) than in those from asymptomatic cases (11.1\%). Six of the 12 plaques with ulceration showed intraplaque hemorrhage in the symptomatic cases. Eight of the 12 plaques with ulceration showed intraluminal thrombus in the symptomatic cases. Intraplaque hemorrhage was found in 17 of the 45 plaques (37.8\%) and was more frequent in the plaques of symptomatic cases (48.1\%) than those of asymptomatic cases (22.2\%). Six of the 13 plaques with intraplaque hemorrhage showed ulceration in the symptomatic cases. Intraluminal thrombus was observed in 10 of the 45 plaques (26.7\%) and more frequently in the plaques of symptomatic cases (37.0\%) than in those of asymptomatic cases (11.1\%). All plaques were divided into three broad degrees of stenosis groups $(40-69 \%, 70-89 \%, 90-99 \%)$ angiographically. The incidence of simple fibrous plaques were most frequent in the most stenotic group, both when all plaques were considered and when only symptomatic plaques were examined. Although ulceration occurred more commonly in the $70-89 \%$ stenosis group, it was also observed in 4 plaques with relatively mild stenosis, and observed in only one plaque with more than $90 \%$ stenosis. Intraplaque hemorrhage occurred more commonly in the stenotic groups with more than $70 \%$ stenosis, whether all plaques or only symptomatic plaques were examined. These findings indicate that: 1) when stenosis of the carotid artery is severe, simple fibrous plaque may cause cerebral ische-
\end{abstract}

${ }^{1}$ 国立循環器病センター 脳神経外科, ${ }^{2}$ 同 研究所, ${ }^{3}$ 同 病理, ${ }^{4}$ チューリッヒ大学 脳神経外科(受稿 1993.8.10)〔連絡先：干565 吹 田市藤白台 5-7-1 国立循環器病センター 脳神経外科 深尾繁治〕〔Mailing address: Shigeharu FUKAO, M.D., Department of Neurosurgery, National Cardiovascular Center, Fujishirodai, Suita 565, Japan] 
mia due to flow restriction, but a critical or hemodynamically significant internal carotid artery stenosis may be of a higher grade than previously appreciated when the lesion is a simple plaque, 2) ulceration of a carotid plaque is seen at a smaller plaque size and induces cerebral ischemia due to embolic phenomena, 3) since intraplaque hemorrhage may contribute to the acute progression of carotid stenosis, hemorrhage may cause hemodynamic failure. Intraplaque hemorrhage may also play an important role in ulceration to cause embolic phenomena.

\section{はじめに}

頸部頸動脈粥状硬化性病変が虚血性脳血管障害の原因と なる機序については，おもに2つの機序が考えられている。 第一に頸動脈粥腫からの塞栓であり，第二に内頸動脈の高 度狭窄による血流低下である. 従来, 頸動脈内膜剥離術の 摘出標本の病理学的所見から脳虚血の成因についてさまざ まな議論が行われてきた．他方，本邦におけるこれらの病 理学的検討は極めて少なく12)19)，また日本人では欧米人 と病理学的にも異なるという意見がある ${ }^{19)}$. われわれは, 頸動脈内膜剝離術の摘出標本を病理学的に検討し, 脳虚血 の発症機序について考察した。

\section{対象および方法}

対象は 1989 年から 1992 年まで当科において頸動脈内膜 剥離術を行った 55 件のうち，摘出標本の保存状態の良好 な 35 症例からの 45 件の頸動脈漱腫である. 男性 32 例, 女性 3 例, 年齢は 41 歳から 79 歳 (平均 65.3 歳)であった. 10 例は両側の内膜剝離術を行っている.

まず内膜剥離術の術中所見から頸動脈洣腫の性状を観察 した後, 摘出標本の横断面について作成した連続パラフィ ン切片にHE, Elastica Van Gieson, Masson trichrome および PTAH 染色を施し, 光顕所見を検討した. それぞ れの頸動脈粥腫について粥腫の破綻に伴う潰瘍形成, 粥腫 内出血, 壁在血栓などの有無を調べた.

45 件の頸動脈粥腫のうち症候性 (symptomatic, 以下 S
群) と考えられたものは 27 件である.これらはNASCET の方法 ${ }^{16)} に$ 従って片麻疩, 一眼の失明などの TIA, strokeで発症したものとし，最終発作から手術までの期間 は平均 4.6 力月であった。無症候性 (asymptomatic, 以下 A 群) と考えられたものは 18 件であった. 後者は両側の 頸動脈病変を有し対側の頸動脈閉塞あるいは狭窄により 症状を発現したもの，または cervical bruit のみの高度狭 窄例が含まれている。術前血管撮影による狭窄度は NASCET の方法 ${ }^{16)} に$ 従った。これら 45 件の頸動脈㑛腫 について, 脳虚血発作の有無および血管撮影上の狭窄度と 内膜の肉眼的, 組織学的所見を対比した． S 群と A 群の 比較には $\chi^{2}$ 検定あるいは Fisher's exact test を用いた。

\section{結 果}

頸動脈粥腫の形態的特徵を simple plaque, 潰痬形成, 粥腫内出血, 壁在血栓の 4 種類に分け, 脳虚血発作との関 連について検討した. Table 1 に S 群とA 群における粥 腫の性状の内訳を示した。 以下にそれぞれの形態的特徵の 典型例を示し要点をまとめる。

\section{1. simple plaque}

潰瘍や码腫内の出血を認めず表面が平滑な粥腫を simple plaque とした. simple plaque は 45 件中 18 件で認め, $\mathrm{S}$ 群 ( 8 件)に比し $\mathrm{A}$ 群 (10 件)で多くみられた。

Table 1 Comparison of incidence of symptomatic and asymptomatic carotid plaques demonstrating any of four major morphologic characteristics

\begin{tabular}{lcccc}
\hline & Simple & Ulceration & Hemorrhage & Thrombus \\
\hline Symptomatic $(\mathrm{n}=27)$ & 8 & 12 & 13 & 10 \\
& $29.6 \%$ & $44.4 \%$ & $48.1 \%$ & $37.0 \%$ \\
Asymptomatic $(\mathrm{n}=18)$ & 10 & 2 & 4 & 2 \\
& $55.6 \%$ & $11.1 \%$ & $22.2 \%$ & $11.1 \%$ \\
Total $(\mathrm{n}=45)$ & 18 & 14 & 17 & 12 \\
& $40.0 \%$ & $31.1 \%$ & $37.8 \%$ & $26.7 \%$ \\
Chi-square significance* & N.S. & $p<0.02$ & N.S. & N.S. \\
\hline
\end{tabular}

*Compared with plaques not showing the morphologic characteristics. N. S. $=$ not significant, $p>0.05$ 


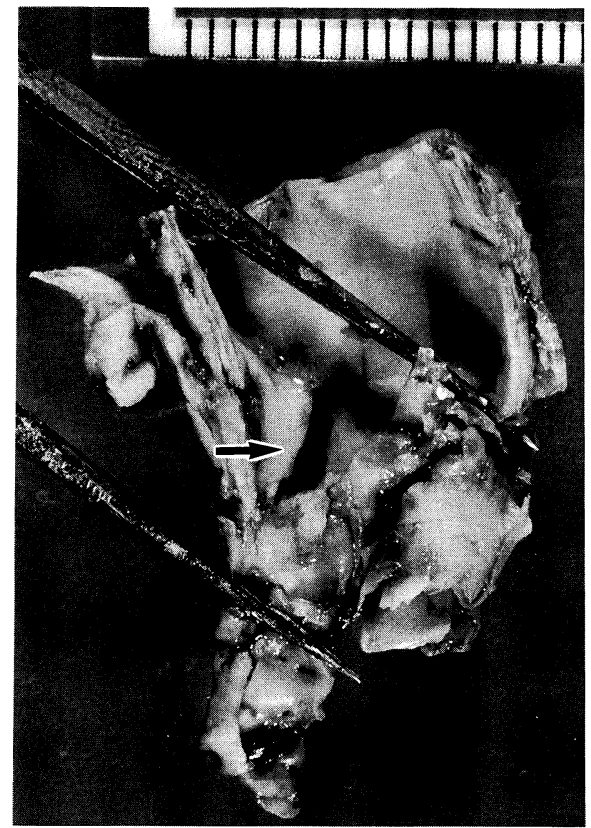

Fig. 1 Macroscopic finding of a surgical specimen obtained from a symptomatic patient. A distinct ulceration (arrow) is seen on the internal surface of the specimen opened longitudinally.

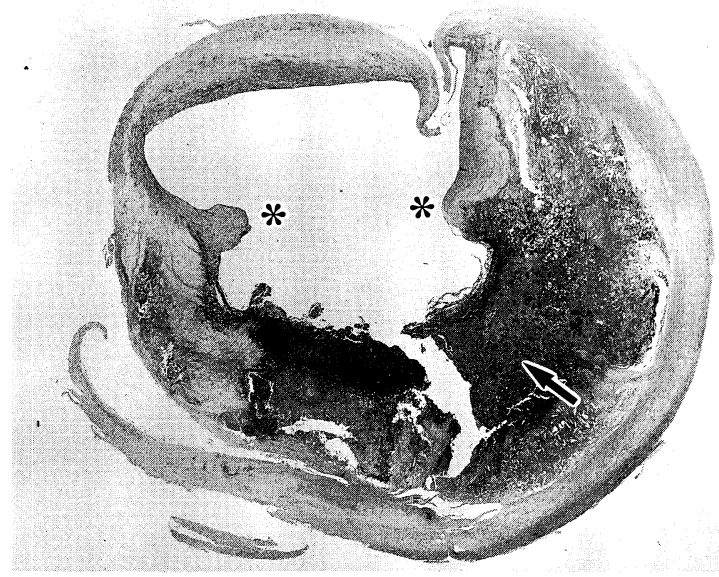

Fig. 2 Photomicrograph of a cross section of a plaque obtained from a symptomatic patient. Plaque ruptuere (between asterisks) and ulcer formation of a plaque with intraplaque hemorrhage (arrow). H\& E stain, $\times 18$.

\section{2. 潰瘍形成}

潰瘍形成は主に病理所見を重要視し，悚腫が断裂し内膜 下層あるいは中膜が露出しているものを潰瘍と判断した (Fig. 1，2). 继腫の潰瘍形成は 45 件中 14 件 (S 群 12 件, $\mathrm{A}$ 群 2 件) で認め, 明らかに S 群に多くみられた $(p<$ 0.02).また潰瘍は壁在血栓, 㑛腫内出血を合併すること

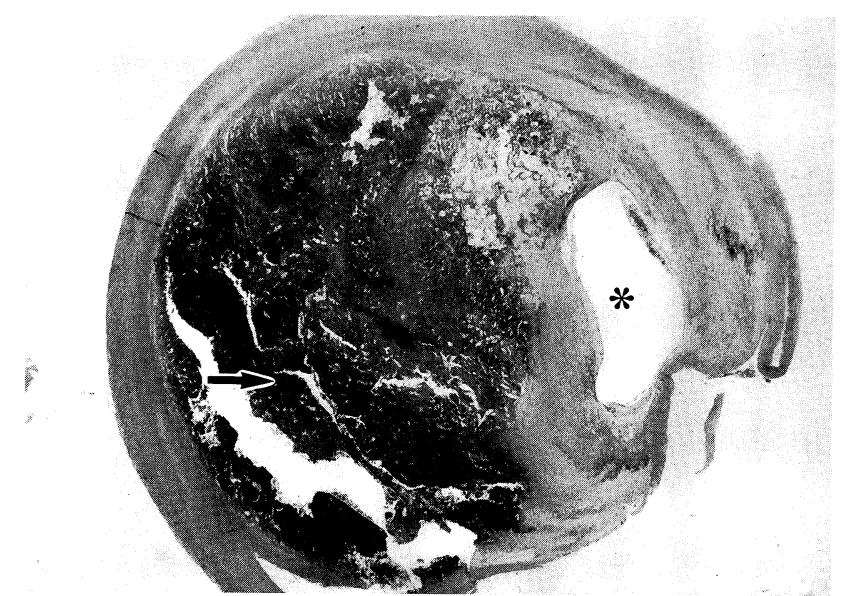

Fig. 3 This cross section obtained from a symptomatic patient shows a massive intraplaque hemorrhage (arrow), which caused diameter reduction of more than $90 \%$ (asterisk). H\&E stain, $\times 18$.

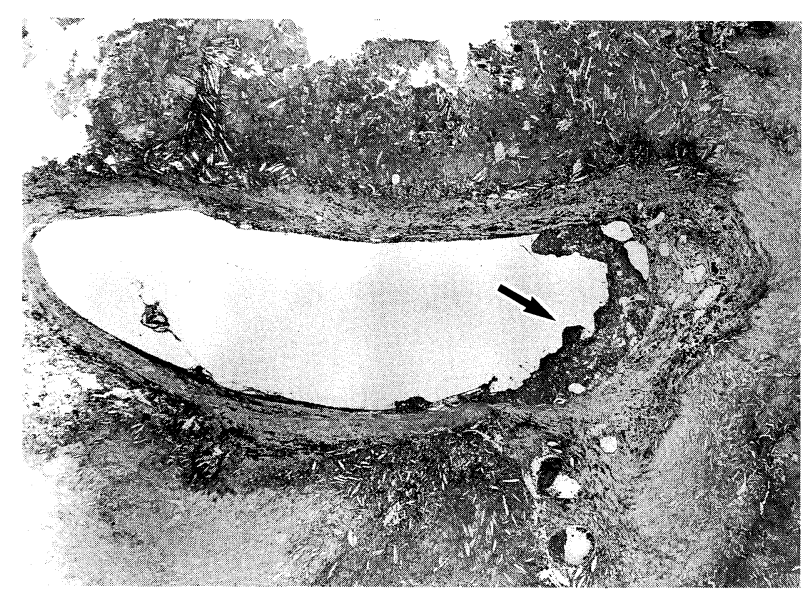

Fig. 4 Photomicrograph of a cross section of a plaque obtained from a symptomatic patient. Plaque rupture and a platelet-fibrin thrombus (arrow) is seen on the luminal surface of the plaque. $\mathrm{H} \& \mathrm{E}$ stain, $\times 34$.

が多く 14 件中 8 件に壁在血栓, 6 件に粥腫内出血がみら れ，これらはすべて S 群であった。

\section{3. 弹腫内出血}

断腫内出血は術中 arteriotomy を加えた時点で明らかな 出血を判定できたものと, 病理学的にはじめて診断された ものとがあった(Fig. 3). 张腫内出血は全標本 45 件中 17 件に認め, $\mathrm{S}$ 群で 13 件, $\mathrm{A}$ 群で 4 件みられた。 また㑛腫 内出血の認められた 17 件のうち 6 件は同時に潰瘍形成が みられこれらはいずれも $\mathrm{S}$ 群であった。さらにこれら の中には出血巣の一部と潰瘍との間に連続性が確認できた ものもあった(Fig. 2). また, 粥腫内出血の認められた症 例のうち 3 例では潰瘍形成はなく, 壁在血栓が認められた。 
Table 2 Comparison of incidence of symptomatic carotid plaque morphologic characteristic among degree of stenosis groups

\begin{tabular}{ccccc}
\hline Degree of stenosis & Simple & Ulceration & Hemorrhage & Thrombus \\
\hline $40-69 \%(\mathrm{n}=4)$ & 1 & 3 & 1 & 2 \\
& $25.0 \%$ & $75.0 \%$ & $25.0 \%$ & $50.0 \%$ \\
$70-89 \%(\mathrm{n}=10)$ & 1 & 8 & 6 & 5 \\
& $10.0 \%$ & $80.0 \%$ & $60.0 \%$ & $50.0 \%$ \\
$90-99 \%(\mathrm{n}=13)$ & 6 & 1 & 6 & 3 \\
& $46.2 \%$ & $7.7 \%$ & $46.2 \%$ & $23.1 \%$ \\
Total $(\mathrm{n}=27)$ & 8 & 12 & 13 & 10 \\
\hline
\end{tabular}

Table 3 Comparison of incidence of asymptomatic carotid plaque morphologic characteristic among degree of stenosis groups

\begin{tabular}{ccccc}
\hline Degree of stenosis & Simple & Ulceration & Hemorrhage & Thrombus \\
\hline $40-69 \%(\mathrm{n}=3)$ & 0 & 1 & 1 & 1 \\
& $0.0 \%$ & $33.3 \%$ & $33.3 \%$ & $33.3 \%$ \\
$70-89 \%(\mathrm{n}=9)$ & 7 & 1 & 1 & 0 \\
& $77.8 \%$ & $11.1 \%$ & $11.1 \%$ & $0.0 \%$ \\
$90-99 \%(\mathrm{n}=6)$ & 3 & 0 & 2 & 1 \\
& $50.0 \%$ & $0.0 \%$ & $33.3 \%$ & $16.7 \%$ \\
Total $(\mathrm{n}=18)$ & 10 & 2 & 4 & 2 \\
\hline
\end{tabular}

\section{4. 壁在血栓}

壁在血栓は術中 arteriotomy を加えた後，ヘパリン加生 理食塩水で irrigation を行いfresh な血液と区別した。さ らに病理所見から具体的に判定した (Fig. 4). 壁在血栓は 45 件中 12 件で認め, $\mathrm{S}$ 群で 10 件, $\mathrm{A}$ 群で 2 件みられた. これら 12 件のうち 8 件は潰瘍内に血栓が認められたもの であり, いずれも $\mathrm{S}$ 群であった.

次に $\mathrm{S}$ 群と $\mathrm{A}$ 群における術前の内頸動脈狭窄の程度と 頸動脈浜腫の性状との関係をそれぞれ Table 2 と Table 3 に示した. 45 件の内頸動脈狭窄の程度はいずれも $40 \%$ 以 上で平均 $82.3 \%, \mathrm{~S}$ 群の 27 件では平均 $81.7 \%, \mathrm{~A}$ 群の 18 件では平均 $83.1 \%$ であった.

S 群 (Table 2) では, $70 \%$ 未満の中等度狭窄例の 4 件中 3 件で潰瘍形成が認められた. 70 ～89\%の狭窄例は 10 件 で, simple plaque は 1 件と少なく, 潰瘍, 粥腫内出血, 壁在血栓が多くみられた。血管撮影でほとんど線状にしか 造影されない $90 \%$ 以上の高度狭窄例は 13 件で, simple plaque ( 6 件), 樔腫内出血 ( 6 件)がほとんどで，潰瘍は 1 件のみであった。

A 群 (Table 3) では, 70 89\%の狭窄例は 9 件で，この うち 7 件は simple plaque であった. $90 \%$ 以上の高度狭窄 例は 6 件で, simple plaque ( 3 件) と码腫内出血 ( 2 件) が 多く，潰瘍形成はみられなかった。

\section{考察}

頸動脈病変に対する治療を検討するに際しては, 頸動脈 病変と一過性脳虚血発作を含む脳卒中との因果関係につい ての十分な理解が要求される. 頸動脈病変と脳卒中との因 果関係は, 閉塞病変に伴う脳血流減少によるところのいわ ゆる脳血流不全と, 頸動脈病変が脳血管への塞栓源となり うるとする 2 点が中心となっている. 従来脳虚血の原因と して脳血流不全症が重要視されていたのに対して ${ }^{7)}$, 最近 では塞栓としてのメカニズムがより重要視されるようにな ってきた ${ }^{3) 49}$ ). 本検討に扔いても潰瘍や壁在血栓が $\mathrm{S}$ 群 で多く観察され, 脳虚血の病因としての脳塞栓機序は重要 な位置を占めていることは明らかである。一方, 潰瘍や壁 在血栓を合併しない頸動脈病変が $\mathrm{S}$ 群の高度狭窄例で多 く見られたことは脳虚血の原因として脳血流不全も少なか らず存在することを示唆するものである.

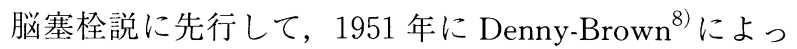
て提唱された脳血流不全症は脳虚血の成因を考える上で重 要である. 頸動脈病変を脳血流不全症として意義づける場 合, 狭窄の程度が問題となる. 内膜の肥厚のみで潰瘍や哆 腫内出血がみられないもの (simple plaque) は, S 群では $90 \%$ 以上の高度狭窄を示す症例が大部分であるのに対して $\mathrm{A}$ 群では 70 89\%の狭窄例に多く，一部は $90 \%$ 以上の高 
度狭窄例でも観察された。このことは頸動脈に慢性に進行 した狭窄のために脳血流不全が起こり脳虚血症状を発現し たと考えられる。しかし慢性に進行した頸動脈病変では, たとえ $90 \%$ 以上の高度狭窄でも症状を発現しない症例が 存在し, これは側副路の発達が大きく関与していると考え られる。

頸動脈に完全な閉塞が存在しても, 必ずしも症状が発現 するというわけではない.このことは側副路以外にも, 頭 蓋内に塞栓が発症していないかどうかと大きく関係してい る.しかし, 脳血流不全症を論じるにあたっては, 実際ど の程度の狭窄が存在すれば脳血流が低下するか (critical stenosis) という基本的問題点を認識する必要がある. Brice $ら^{6)}$ によれば，狭窄部より末梢で優位な血流減少を きたすのは残留管腔の直径が $2 \mathrm{~mm}$ 以下となった場合とい

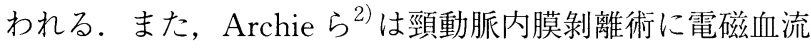
計を用いて critical stenosis を検討した結果，血管径 75\% 以上, 血管面積 $94 \%$ 以上の狭窄が優位な血流低下を生じ ると報告している。これらの知見は，単に閉塞性頸動脈病 変のみから脳血流不全症の発症機序をみた場合に，極めて 高度な狭窄が存在しなければならないことを意味するもの である．頸動脈啉腫の性状から見た本検討においてもこの ことが証明されたわけである。

脳虚血の成因として, 脳塞栓説は今日もっとも注目され ているものである．頸動脈病変，心臓病変などの頭蓋外の 血管病変に由来する塞栓子が脳に飛来することによるとす る説である．頸動脈病変の塞栓症の原因となる血栓の形成 には以前より頸動脈洣腫の潰瘍の存在が重要視されてきた 3) 4) 9). 今回の結果でも潰瘍形成がみられた頸動脈粥腫 14 件のうち 8 件 (57.1\%) は同時に壁在血栓を合併しており, これらはすべて $\mathrm{S}$ 群であった.つまり内膜肥厚部位に潰 瘍形成がある場合には，末梢部への塞栓を生じやすいとい える.

潰瘍は頸動脈の狭窄の程度に並行して出現頻度を増すと され，血行力学的に血流不全を生じる程度の狭窄病変は， よりいっそう塞栓源になりやすいと考えられている ${ }^{4) 9)}$. 本検討では 70 89\%の狭窄を示す症例に多くみられ, 狭 窄度が $69 \%$ 以下でも 4 件にその存在が認められ，逆に $90 \%$ 以上の高度狭窄では潰瘍がみられたのは 1 件のみであ った.これは，頸動脈病変を塞栓源として意義づける場合 狭窄の程度は問題とならないことを意味する，さらに，極 めて高度の狭窄性病変では脳血流不全の影響が大きくなり 脳塞栓症で発症するものは少ないことを証明している。

潰瘍の発生機序を考える上で注目に值することは, 潰瘍 形成の認められた 12 件のうち 6 件が同時に粥腫内出血を 合併し，さらに一部の症例ではその出血巣が部分的に潰瘍 まで連続していた点である。これは内膜が断裂して潰瘍が
形成される機序に粥腫内の出血が深くかかわっているとす る意見を支持する所見といえる. Lusby ら ${ }^{15)}$ は潰瘍は出 血のある部位に一致して多くみられたことから, 出血が契 機になって内膜の破綻が起こって潰瘍が形成されるのでは ないかと推測している. また, Persson ら ${ }^{17) 18)}$ は出血が潰 瘍形成の原因になるのみならず，それ自体が血管内腔に露 出して塞栓源となる可能性もあるとしている. 今回, 潰瘍 形成の認められた半数に粥腫内出血が合併していた事実は 粥腫内の出血が潰瘍の形成を促し, 塞栓の発生に関与する 可能性を示唆するものであった。

頸動脈洣腫の性状のうち, 粇腫内の出血は脳虚血発作と の関連や潰瘍形成の機序を考える上で重要であり, 以前か ら繰り返し議論されてきた. 頸動脈内膜剥離術の摘出標本 の最近の報告では脨腫内の出血は $\mathrm{A}$ 群に比し $\mathrm{S}$ 群で多く 観察されている ${ }^{10) 12) 13) 15) 17) . ~ I m p a r a t o ~}{ }^{13)}$ は, 摘出した 症候性あるいは無症候性の 376 件の頸動脈粥腫の肉眼的に みえる潰瘍, 出血, 血栓などの所見について脳虚血発作の 有無と対比した結果, 粥腫内の出血がある例に脳虚血発作 が多く, 狭窄が高度で, 発作がみられる例に粥腫内の出血 が多いことをあげている. Lusby ら ${ }^{15)}$ は摘出した頸動脈 粥腫の組織学的所見と脳虚血発作との関連を検索した結果 53 件の頸動脈粥腫のうち 49 件 $(92.5 \%)$ に新しい出血がみ られ，無症状の 26 件の坫腫には 7 件 $(26.9 \%)$ にしか新し い出血はみられなかった. また, 潰瘍は粥腫内の出血のあ る部位に発生し, 悚腫内に出血がある場合は潰瘍がなくて も壁在血栓がみられることがあったと報告している．すな わち Imparato ら, Lusby らは粥腫内の出血が脳虚血発作 の重大な役割を担うと述べており，その機序としては，粥 腫内の出血により内腔狭窄が高度となるとか, 出血により 種々の凝固因子などが内腔面ににじみ出て壁在血栓を作 るのではないかと考えられている。また前述のごとく Persson ら ${ }^{16) 17)}$ は上記の機序に加えて, 出血が内腔に達す ることが症状を発現させる重要な点であるという成績を出 している. しかし，一方では泟腫内の出血の頻度と症状の 発現との間にはまったく相関がなかったとする報告1)14) や 脳虚血発作の時期と㑛腫内出血の発現時期との間には相関 が見られなかったとする報告 ${ }^{\left.1{ }^{5}\right)}$ があり，いまだ意見の一 致はみられていない.われわれの検討では, $\mathrm{S}$ 群で粥腫内 の出血が多くみられたこと, また $70 \%$ 以上の高度狭窄例 で粥腫内の出血が多く観察されたことから, 出血により急 激な粥腫の拡大が生じて脳血流不全を起こし, 脳虚血発作 を発現したと考えるのが妥当である.さらに上述のように 粥腫内の出血は潰瘍形成を促し, 塞栓の原因としても重要 であることは十分考えられる。

以上のごとく頸動脈病変の脳虚血の発症機序は, けっし て単一のものではない. 閉塞性内頸動脈病変の治療に関し 
ては，脳血流不全と塞栓源というふたつの機序を常に念頭 において対処する必要があろう。

\section{結 語}

頸部頸動脈㑛状硬化症の病理学的所見から脳虚血の発症 機序を検討した．脳虚血症状発現の要因としては，比較的 狭窄の少ないものでは潰瘍，壁在血栓による塞栓が関与し ている，粥腫内に生じた出血は急激に内腔を狭窄させ低灌 流を起こすとともに潰瘍の形成を促し，塞栓の発生に関与 する可能性を示唆するものであった。 また，慢性に進行し た頸動脈病変による脳血流不全症は, 極めて高度な狭窄が 存在しなければならないことを示すものであった.

\section{文献}

1) Ammar $\mathrm{AD}$, Wilson $\mathrm{RI}$, Travers $\mathrm{H}$, et al: Intraplaque hemorrhage: Its significance in cerebrovascular disease. Am J Surg 148: 840-843, 1984.

2) Archi JP Jr, Feldtman RW: Critical stenosis of the internal carotid artery. Surgery 89: 67-72, 1981

3) Bartynski WS, Darbouze P, Nemir P Jr: Significance of ulcerated plaque in transient cerebral ischemia. Am J Surg 141: 353-357, 1981

4) Blaisdell FW, Glickman M, Trunkey DD: Ulcerated atheroma of the carotid artery. Arch Surg 108: 491-496, 1974

5) Bornstein NM, Norris JW: The unstable carotid plaque. Stroke 20: 1104-1106, 1989

6) Brice JG, Dowset DJ, Lowe RD: Haemodynamic effects of carotid artery stenosis. Br Med J 2: 1363-1366, 1964

7) Corday E, Rothengerg SF, Putnam TJ: Cerebral vascular insufficiency. An explanation of some types of localized cerebral enceplalopathy. Arch Neurol Psychiatry 69: 551570,1953
8) Denny-Brown D: The treatment of recurrent cerebrovascular symptoms and the question of "vasospasm". Med Clin North Am 35: 1457-1474, 1951

9) Edwards JH, Kricheff II, Riles T, et al: Angiographically undetected ulceration of the carotid bifurcation as a cause of embolic stroke. Neuroradiology 132: 369-373, 1979

10) Fisher CM, Ojeman RG: A clinicopathologic study of carotid endarterectomy plaques. Rev Neurol 142: 573-589, 1986

11) Fisher M, Blumenfeld AM, Smith TW: The importance of carotid artery plaque disruption and hemorrhage. Arch Neurol 44: 1086-1089, 1987

12）古井倫士，長坂徹郎：頸部頸動脈閉塞性病変の病理学的検 討. 脳神経外科 $21 ：$ 425-430, 1993

13) Imparato AM, Riles TS, Mintzer R, et al: The importance of hemorrhage in the relationship between gross morphologic characteristics and cerebral symptoms in 376 carotid artery plaques. Ann Surg 197: 195-203, 1983

14) Lennihan L, Kupsky WJ, Mohr JP et al: Lack of association between carotid plaque hematoma and ipsilateral cerebral symptoms. Stroke 18: 879-881, 1987

15) Lusby RJ, Ferrell LD, Ehrenfeld WK, et al: Carotid plaque hemorrhage. Arch Surg 117: 1479-1488, 1982

16) North American Symptomatic Carotid Endarterectomy Trial (NASCET) Steering Committee: North American Symptomatic Carotid Endarterectomy Trial, Methods, $\mathrm{Pa}$ tient Characteristics, and Progress. Stroke 22: 711-720, 1991

17) Persson AV: Intraplaque hemorrhage. Surg Clin North Am 66: 415-420, 1986

18) Persson AV, Robichaux WT, Silvermann M: The natural history of carotid plaque development. Arch Surg 118: 1048-1052, 1983

19）山田和雄, 早川 徹, 伊藤 守: 細胞病理学的側面よりみ た頸動脈粥状硬化症と内膜剝離術. Neurosurgeons $\mathbf{9}$ : 240-249, 1990 